\title{
CARACTERIZAÇÃO GEOMORFOLÓGICA E AVALIAÇÃO AMBIENTAL DA FRAGILIDADE DAS VERTENTES NO BAIRRO DE TABATINGA, MUNICÍPIO DE CAMARAGIBE - PE \\ Niédja Maria Galvão Araújo e Oliveira ${ }^{1}$ João Allyson Ribeiro de Carvalho ${ }^{2}$ \\ Paulo Henrique de Santana ${ }^{3}$
}

\begin{abstract}
Resumo: A presente pesquisa tem como objetivo analisar, em plano evolutivo, a geomorfologia ambiental das formas que, como objeto dinâmico, reflita ambientes indutores à ocorrência de deslizamentos, avaliando os fatores responsáveis, direta e indiretamente, pela resistência do solo à erosão. Esta é uma proposta de ação integrada, que provê a caracterização geomorfológica ambiental do sistema de movimento de massa, nas áreas de colinas dos Glacis de acumulação no Bairro de Tabatinga, município de Camaragibe, inserido no Grupo Barreiras. No tocante à metodologia, foram realizadas análises mineralógicas, monitoramento bimestral dos taludes e verificação da erosão de suas bordas. Para identificação e avaliação dos impactos, utilizaram-se idéias de LEOPOLD (1994) e GOMEZ (1994), adaptadas por OLIVEIRA (1998). Como resultados da análise mineralógica, pôde-se diagnosticar predominância de argila $(56,8 \%)$. As vertentes sofrem perda significativa segundo dados monitorados. No que se refere à avaliação dos impactos, identificaram-se 27 casos. Do total, apenas quatro foram positivos.
\end{abstract}

Palavras-Chave: Degradação Ambiental; Movimento de Massa; Deslizamento; Risco Geológico.

\section{Introdução}

A ocupação territorial do Brasil iniciou-se, de fato, a partir de 1530. A forma como tal território foi ocupado repercute até hoje e pode repercutir no futuro, se medidas eficazes não forem tomadas. Uma das principais formas de ocupação do território brasileiro, sobretudo no nordeste, foram as instalações dos engenhos e sua monocultura de cana-de-açúcar. A ocupação pela atividade açucareira em Pernambuco deu-se em uma grande faixa que compreende o litoral, zona da mata e alguns setores do agreste e sertão.

Nessa parte, vários municípios tinham, em seu território, a maior área ocupada pela monocultura canavieira, muitas vezes, servindo como a única fonte geradora de riqueza, como se exemplifica pelo município objeto de estudo, Camaragibe (Fig. 1). Apesar de tal região ter origem a partir de um distrito de um outro município, São Lourenço da Mata, a principal característica que a distingue de São Lourenço da Mata, é a proximidade da capital pernambucana. Fato base para justificar a intensidade da ação antrópica que altera a paisagem ao longo dos séculos. 0 território foi palco de grandes desmatamentos para a implantação da monocultura canavieira, em detrimento da Mata Atlântica nativa. Dentre os agentes responsáveis por esse processo estão os engenhos Timbi e Camaragibe, que datam de 1549.
Posteriormente, com o aprimoramento do processo de industrialização, cederam espaço para a indústria têxtil, Companhia Industrial Pernambucana (CIP), Braspérola, acompanhada da primeira vila operária da América Latina, fato que contribuiu para uma explosão urbana. Há pouco mais de uma década, a indústria fechou; recentemente, porém, existem projetos intencionados em sua reabertura.

O próprio aprimoramento da urbanização e industrialização do Município contribuíram para o "inchaço" da cidade, fenômeno demográfico comum em capitais e cidades adjacentes. Como principal conseqüência, pode-se identificar a fixação da população menos favorecida em áreas de instabilidade geológica, caracterizada pelos glacis de acumulação do Grupo Barreiras, região com predomínio de movimentos de massa em decorrência da declividade e composição geológica local. É importante salientar que tais movimentos de massa são potencializados com a presença do homem, com ações como cortes inadequados de vertentes para moradia e deposição de resíduos sólidos a partir do lixo doméstico, a ocorrência de inúmeros deslizamentos nos momentos de precipitação pluviométrica consideráveis, em curtos espaços de tempo, trazendo, inclusive, conseqüências irreversíveis como perda de vida humana.

\footnotetext{
1 Doutora, Professora Titular da Universidade de Pernambuco/UPE - OEM Comunicação/FACEPE/CNPq/FDPE, noliveir@oi.com.br

2 Esp. Professor da Universidade de Pernambuco/UPE, allysondecarvalho@hotmail.com

${ }^{3}$ Bolsista CNPq/UPE, paulosantana26@yahoo.com.br
} 
MUNICÍPIO DE CAMARAGIBE NO ESTADO DE PERNAMBUCO

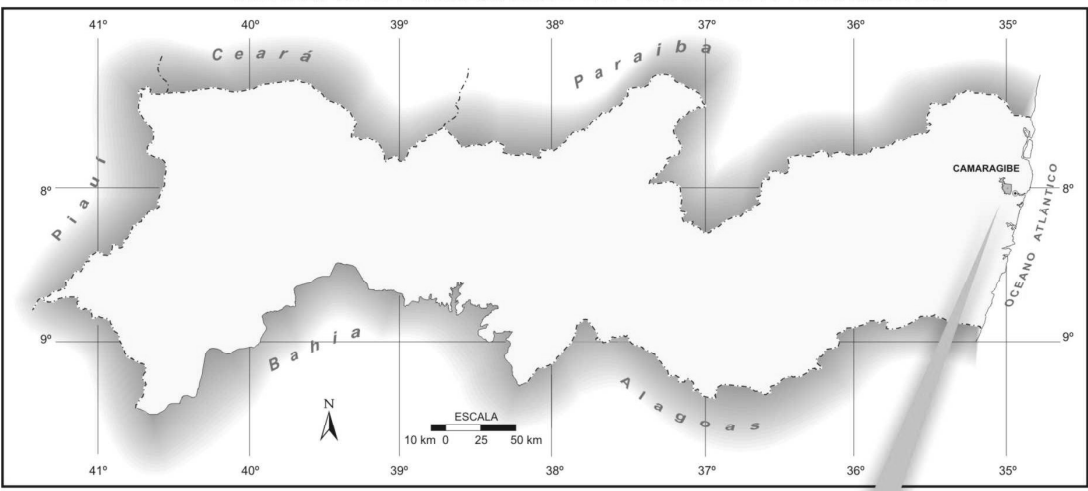

LOCALIZAÇÃO DAS ESTACAS NO MUNICÍPIO DE CAMARAGIBE

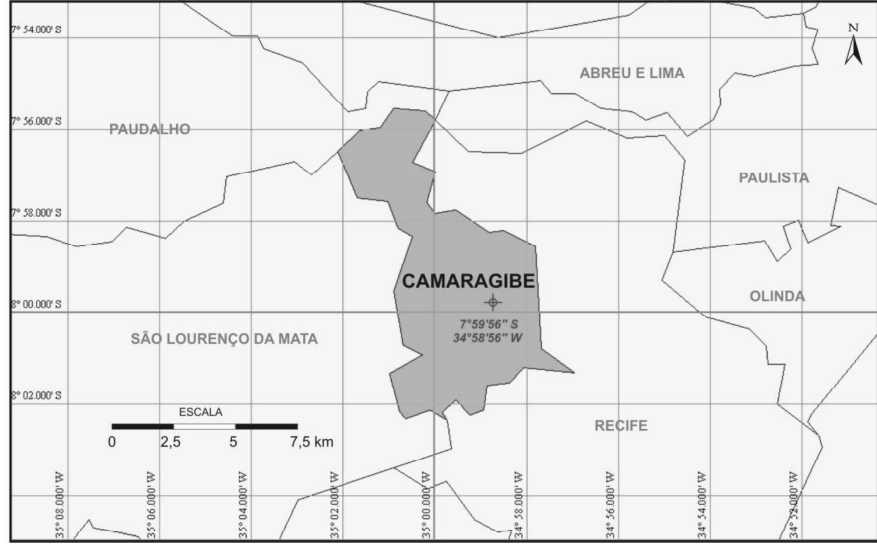

Figura 1 Localização da área de estudo.

O Município de Camaragibe é dividido em cinco áreas administrativas, definidas como distritos municipais. Dos cinco distritos, quatro podem ser vistos como áreas de risco geológico iminente, justificada pela morfologia, facilmente desagregável e intensamente susceptível à erosão hídrica. Formatada por uma estrutura complexa, delicada, faz surgir inúmeras áreas de elevada vulnerabilidade. Fatos que se somam ao clima da área, segundo KÖPPEN, As', pseudotropical, com chuvas de outono e inverno, resultante da Massa Polar Atlântica e da Convergência Intertropical, com um índice de precipitação de $1800 \mathrm{~mm}$ de chuvas anuais, temperatura média de $24^{\circ} \mathrm{C}$ e umidade relativa do ar em torno de $87 \%$.

0 fator umidade reduz ações erosivas. Os quatro distritos somam cerca de quarenta e dois bairros. Uma vasta região insuficientemente monitorada pela Defesa Civil Municipal, que disponibiliza apenas um Engenheiro Civil para cada distrito, sem que haja a presença de outros profissionais em perspectiva $\mathrm{e}$ gestão ambiental, engajados no sentido de minimizar a degradação ambiental em toda a área. Das quatro áreas, a de número quatro compreende os doze bairros de maior ocorrência de deslizamentos e erosões aceleradas, como 0 processo de voçorocamento.

Nos últimos cinco anos, aproximadamente, cinqüenta ruas foram afetadas com deslizamentos no Bairro da Tabatinga, o mais atingido pelos movimentos de massa, sendo, conseqüentemente, área considerada foco de estudo, o que é justificado pela 
intensidade dos processos erosivos e pela complexidade dos fatores atuantes na região em pauta. Sobretudo no trecho delimitado para monitoramento (Fig. 2), que compreende as coordenadas entre $07^{\circ} 59^{\prime} 00^{\prime \prime}$ e $08^{\circ} 00^{\prime} 00^{\prime \prime}$ S, e $34^{\circ} 58^{\prime} 00^{\prime \prime}$ e $34^{\circ} 59^{\prime} 00^{\prime \prime}$ W, uma área, intensamente alterada, caracterizada por uma vertente de aproximadamente 10 metros, que comporta oito casas na parte com menor declive, em decorrência do processo de aterramento por parte dos próprios moradores, acompanhadas de várias outras casas na continuidade da vertente.

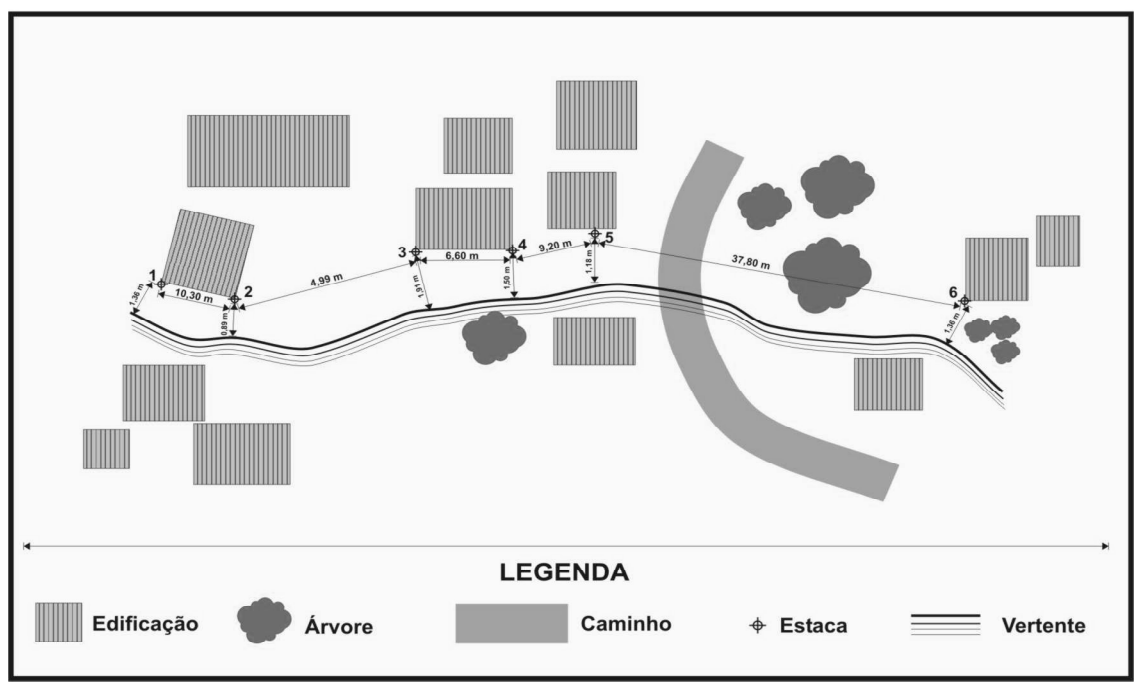

Figura 2 Localização da área monitorada.

Tal estudo torna-se extremamente relevante, uma vez que a área não é acompanhada por nenhuma Instituição de excelência em Pesquisa e apresenta uma densidade demográfica à mercê de acontecimentos naturais que repercutiriam tragédias irreversíveis, sem um monitoramento eficaz com os constantes desabamentos. Tal monitoramento permite conhecer 0 ambiente de modo a identificar sua dinâmica, apontando, ao final, as alternativas de maior viabilidade para recuperação da área em médio e longo prazo. Justificando o objetivo central de reportar-se à análise em plano evolutivo, a geomorfologia ambiental das formas, que, como objeto dinâmico, reflete ambientes indutores à ocorrência de voçorocas e movimentos de massa, avaliando os fatores responsáveis, direta e indiretamente, pela resistência do solo à erosão, proposta de ação integrada, que torne oportuna a caracterização geomorfológica ambiental do sistema de voçorocamento e movimento de massa nas áreas de colinas dos Glacis de acumulação da Formação Barreiras no Bairro de Tabatinga.

\section{Materiais e Métodos}

Envolve material bibliográfico inerente ao assunto, levanta- mentos dos aspectos conceituais dos impactos ambientais aplicados à área em estudo, inclusive pesquisa em jornais da região sobre a ocorrência de deslizamentos ocorridos na área. Modelos de gestão propostos pela bibliografia especializada como os Matriciais, obedecendo aos seguintes critérios: caráter, magnitude, importância e duração. Além de parâmetros avaliados como análise dos sedimentos, análises morfológicas, hidrológicas, flora, estética da paisagem, uso do solo, urbanização e indústria em concomitância com as etapas de campo (monitoramento), laboratório e fotointerpretação.

A escolha das diversas metodologias justifica-se por se tratar de um ambiente intensamente alterado e degradado. Com a implementação dos processos metodológicos, pretende-se chegar a uma interpretação de todo o ambiente de maneira mais fidedigna. Fato imprescindível para adotar políticas e ações fundamentadas no conhecimento científico e eficazes, de modo a excluir qualquer medida pautada no imediatismo, sem que tenha havido um efetivo conhecimento.

Para materialização das metodologias e reconhecimento da região foi necessário identificar todos os impactos resultantes, tanto positivos quanto os negativos. 
A visão holística descrita acima representa uma ferramenta eficaz para se tratar processos erosivos acelerados como as voçorocas, já que o entendimento de sua origem e evolução é imprescindível para apontar ações que representem solução do problema. Nesse contexto, o monitoramento permite conhecer periodicamente a dinâmica do processo erosivo (acréscimo e decréscimo de perda de sedimentos) de uma voçoroca. Este processo é auxiliado pela interpretação de fotografias aéreas, imagens LANDSAT, além do trabalho de campo, em que se observam as alterações expressivas.

Estabelece-se critérios para os limites de alteração do ambiente, já que a degradação ambiental costuma ser um processo que sinaliza gradualmente rompimentos do equilibrio ambiental e, ultrapassando certo ponto crítico, evolui exponencialmente para processos de crise que, na maior parte dos casos, costuma ser irreversível. Identifica-se como principal variável a ser analisada os fatores efetivamente responsáveis pela causa e ocorrência dos movimentos de massa. Fundamenta-se a descrição físico-química geral do regolito dos perfis da vertente estudada pela análise de dados nos laboratórios da Universidade Federal de Pernambuco (UFPE) e da Universidade Federal Rural de Pernambuco (UFRPE), importantes parceiros para diagnose local.

Associado à etapa laboratorial, o monitoramento bimestral representa um importante instrumento para conhecer a dinâmica do grau de erosividade dos taludes. Um processo estritamente ligado ao regime pluviométrico da região.

Com exceção dos equipamentos utilizados em laboratório, pode-se citar os de uso cotidiano nas visitas ao campo, como a bússola e altímetro para identificação do grau de declividade e altura dos taludes monitorados e adjacentes. Higrômetro, para percepção da umidade relativa do ar, expressa em porcentagem. GPS, para localização de cada estaca no processo de monitoramento da voçoroca. Trena para medir a distância entre estaca e vertente, no sentido de identificar o que está preservado e 0 que foi erodido. Além de estacas em madeira com $45 \mathrm{~cm}$, sacos plásticos, espátula e martelo geológico.

No que se refere ao monitoramento da voçoroca, a análise é de analogia: a partir de resultados tomados se define o valor da diferença entre duas aferições consecutivas. Quanto aos deslizamentos, a análise se deu no sentido de caracterizar o tipo de movimento de massa (forma de projeção da massa via vertente), mediante as particularidades e características inerentes a cada tipo de movimento discernida por GUIDICINI e NIEBLE (1984).

Posteriormente, aplicou-se o método de identificação e avaliação de impactos: a avaliação de multicritérios adaptada dos modelos matriciais de LEOPOLD (1994) e GOMEZ (1994) foi empregada para detectar as transformações ocorridas com base em um conjunto de ações humanas, fatores e elementos naturais (físico, bióticos, perceptíveis e socioeconômicos) alterados pelo homem e nos impactos produzidos, obtendo-se uma quantificação global e ponderada dos impactos positivos e negativos. Os critérios qualitativos e quantitativos utilizados contêm caráter do impacto, certeza, tipo, tempo de desenvolvimento e magnitude, importância, duração e reversibilidade.

\section{Resultados e Discussão}

A intensidade dos processos antrópicos permite diagnosticar as múltiplas alterações da paisagem. Fator preponderante para nortear a complexidade do ambiente e a dificuldade de efetivação de reabilitação da área, conforme se observa na Fig. 3 , com área de risco iminente, face o ângulo verticalizado do corte da vertente, induzindo ao deslizamento acima da residência colocada na projeção inferior. Na Fig. 4, constata-se a cultura de banana, com grande capacidade de armazenamento de água, elemento base para o desenvolvimento de deslizamentos. $\mathrm{Na}$ Fig. 5 , verifica-se a intensa forma de ocupação do solo com o talude local totalmente impermeabilizado, interceptando o ciclo natural do sistema hidrológico. A Fig. 6 representa um exemplo concreto de cortes verticalizados induzindo a iminência de deslizamentos.

Figura 3 Trecho da vertente de maior grau de inclinação sem nenhuma

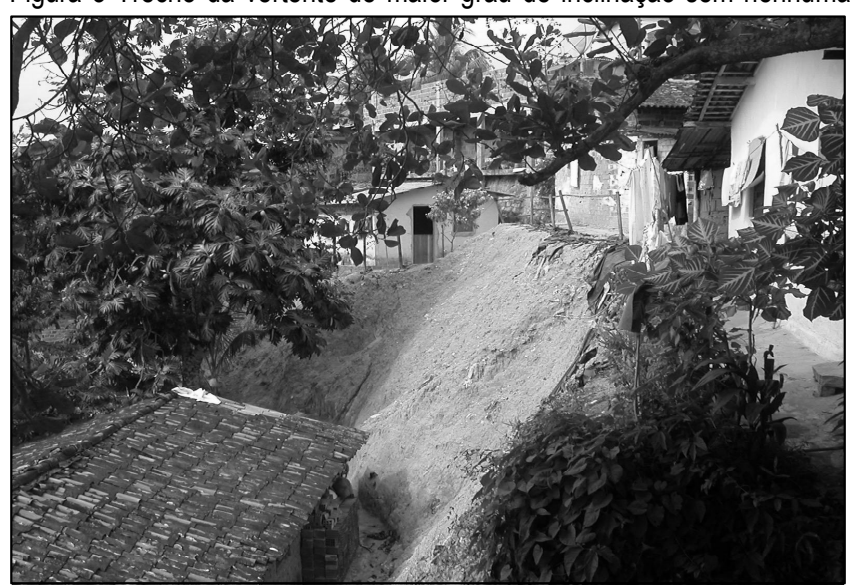

obra de proteção. 


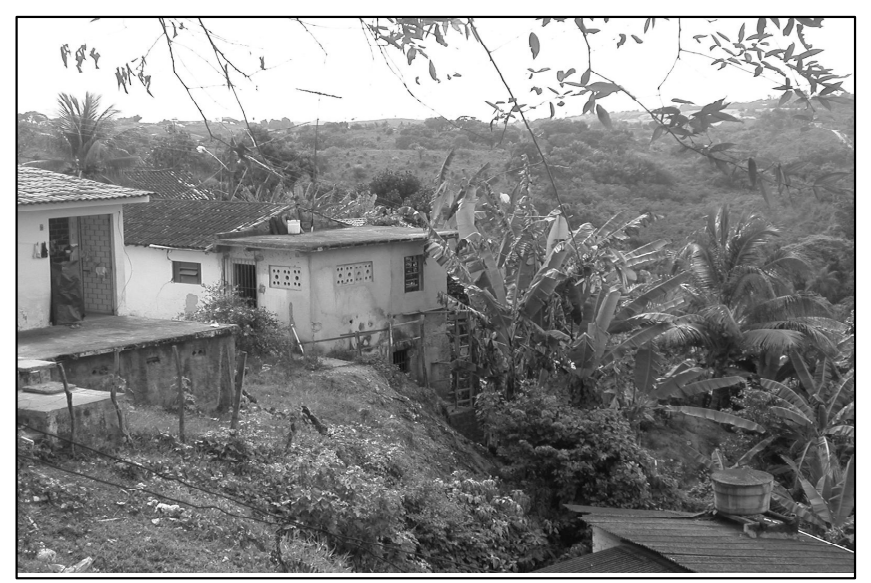

Figura 4 Presença de bananeiras em áreas de vertente íngreme.

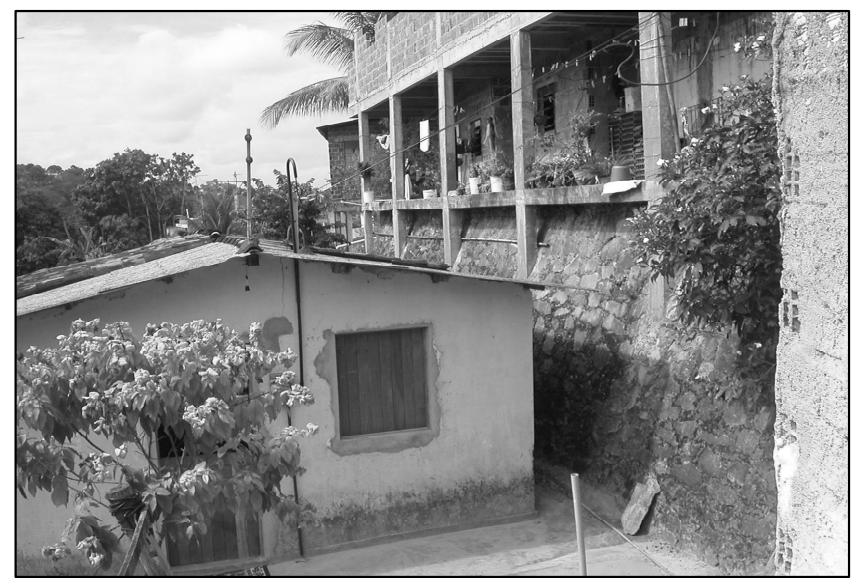

Figura 5 Exemplo da intensa ocupação e verticalização do talude impermeabilizado.

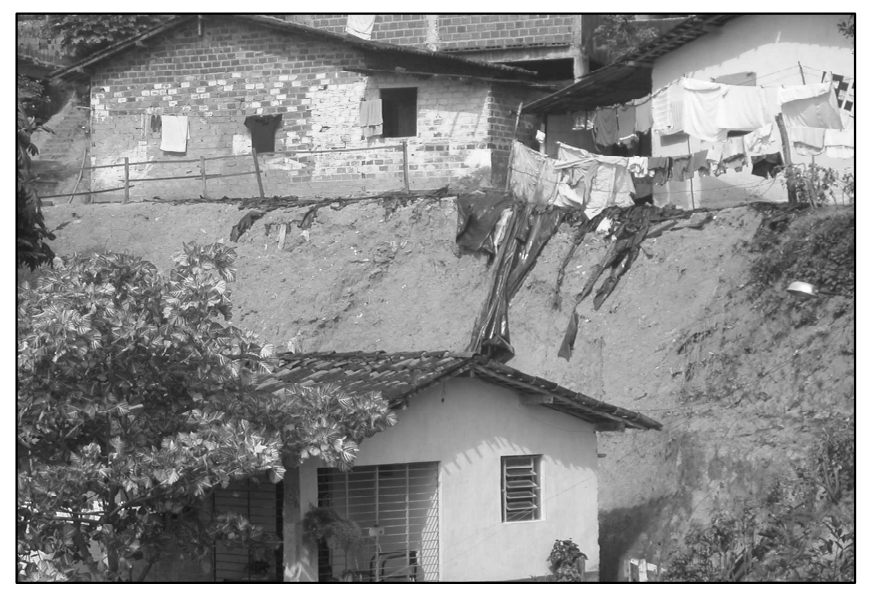

Figura 6 Corte inadequado da vertente.
Para ratificar o processo de desmonte, procede-se a análise de fotografias aéreas e de ortofotocartas, como observado no Recorte 01, datado de 1974 (Fig. 7), com o início do processo de urbanização da área com a construção de casas e com aberturas de ruas e caminhos de acesso no topo da vertente. No Recorte 02, datado de 1981 (Fig. 8), pouco menos de dez anos depois, pode-se notar claramente a grande explosão de residências, não só no topo, mas na área em declive. Já no Recorte 03, correspondendo à ortofotocarta de 1981 (Fig. 9), pode-se constatar as numerosas habitações delineadas pelas curvas de nível e que retratam a altimetria da área em estudo.

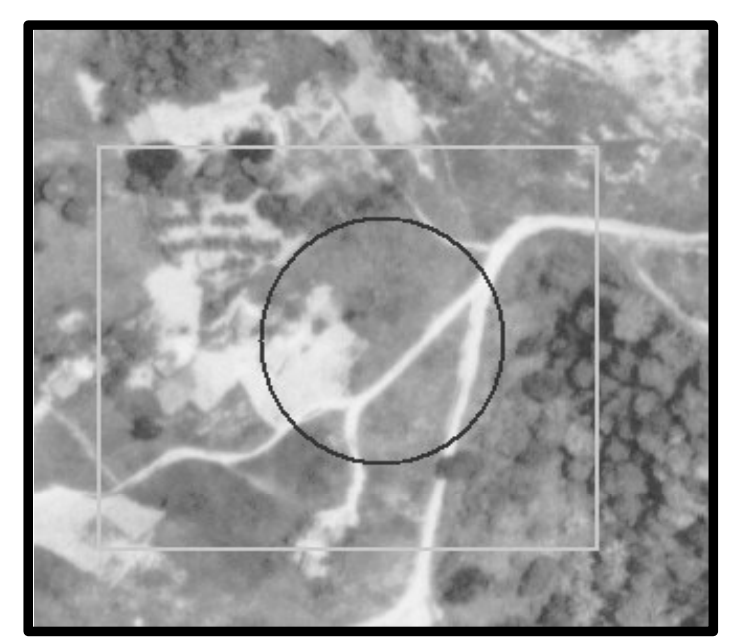

Figura 7 Recorte 01: 1974 - fotografia aérea da área; início do processo urbano acelerado no Município. Fonte: FIDEM, 1974.

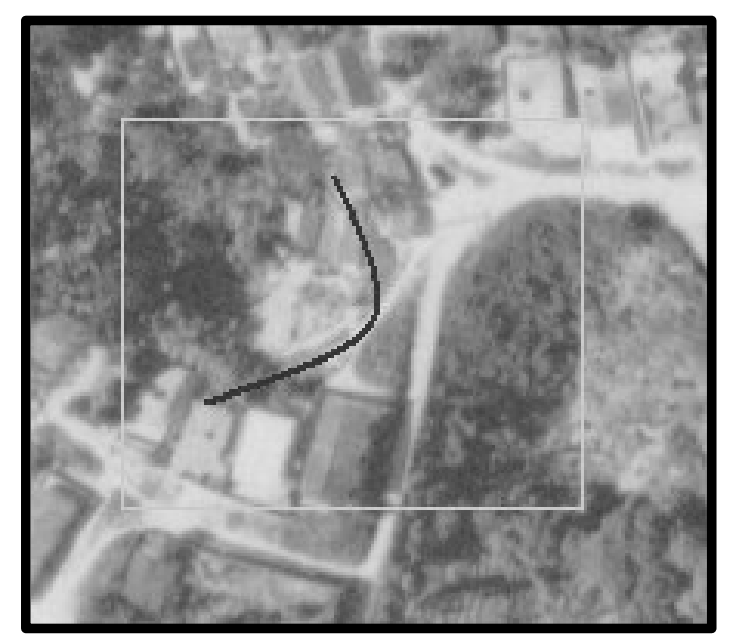

Figura 8 Recorte 02: 1981 - recorte da fotografia aérea da área já intensamente ocupada por residências. Fonte: FIDEM, 1981. 


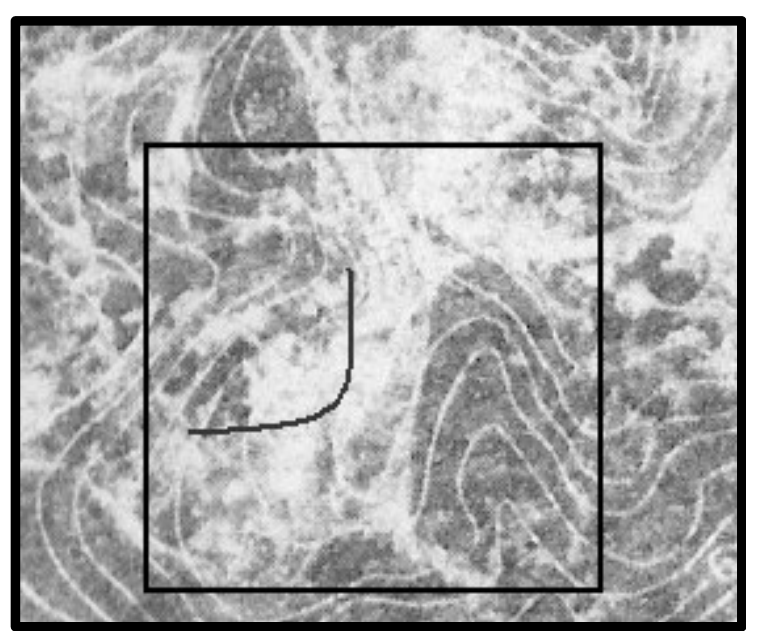

Figura 9 Recorte 03: 1984 - recorte da ortofotocarta da área, com curvas de nível representando o relevo acidentado de grande declividade. Fonte: FIDEM, 1984.

Atualmente, a encosta encontra-se recoberta por lona plástica preta, tal como, segundo a Prefeitura do Município, é a forma utilizada para impedir novos deslizamentos. Sabe-se que este tipo ação é inconsistente, funcionando como medida paliativa e conformização à comunidade. Também ocasionara uma desaceleração no processo de erosibilidade pela chuva, no sistema de erosão por lençol.

Como resultados, pode-se observar na Tab. 1 que os locais de fixação de estacas se dá em diferentes extensões devido ao alto grau de ocupação do talude, de acordo com as imagens vistas anteriormente. Já na Tab. 2, verifica-se que os valores aferidos entre a estaca e a borda do talude não apresentaram modificações perceptíveis entre os meses de agosto/2005 e outubro/2005. A área apresentou estabilidade face à ínfima ocorrência de precipitação pluviométrica na região. Outro aspecto relevante é o fato do talude monitorado representar um exemplo concreto de uma área intensamente alterada, resultante de aterros, construção de habitações, inclusive com a impermeabilização de algumas áreas. Este fato contribui para que a erosão seja minimizada em curto prazo, mas cumulativa, potencializada em médio e longo prazo. Tal fator predispõe o terreno a tragédias, já que a intensidade e abrangência dos movimentos de massa, nesses casos, tendem a ser maiores. Ocorrências dessa natureza são freqüentes nas grandes cidades, impondo altos custos às prefeituras municipais, uma vez que uma política de prevenção não é implementada. Geralmente, a população afetada é de classe menos favorecida, um exemplo típico do processo histórico de uso e ocupação do solo no Nordeste do Brasil.
Tabela 1 Localização das estacas com pontos de referência.

\begin{tabular}{c|l}
\hline ESTACAS & $\begin{array}{l}\text { PONTOS DE REFERÉNCIA COM PRINCIPAIS } \\
\text { CARACTERISTICAS PAISAGISTICAS }\end{array}$ \\
\hline 01 & $\begin{array}{l}\text { Localizada entre as residências } 1 \text { e } 2 . \text { Vertente } \\
\text { exposta com um pequeno muro de contenção. } \\
\text { Cobertura vegetal retirada pela população. }\end{array}$ \\
\hline 02 & $\begin{array}{l}\text { Localizada na residência 2, coberta por gramíneas. } \\
\text { Pequeno muro de contenção. }\end{array}$ \\
\hline 04 & $\begin{array}{l}\text { Localizada após a residência 2, próximo a um corte } \\
\text { no talude abrupto de aproximadamente } 90^{\circ} .\end{array}$ \\
\hline 05 & $\begin{array}{l}\text { Localizada próxima à residência 3. Possui indícios de } \\
\text { cobertura plástica colocada pela Prefeitura no último } \\
\text { inverno completamente deteriorada. }\end{array}$ \\
\hline 06 & $\begin{array}{l}\text { Localizada na residência 3. Local com risco potencial } \\
\text { de deslizamentos. Presença de canais de esgotos em } \\
\text { direção à vertente. Indícios claros de infiltração na } \\
\text { base da vertente por água proveniente de esgoto } \\
\text { doméstico. }\end{array}$ \\
\hline $\begin{array}{l}\text { Localizada na residência 4. Presença de bananeiras } \\
\text { em toda a vertente, contribuindo para o solapamento } \\
\text { do material com risco potencial de deslizamento. }\end{array}$ \\
\hline
\end{tabular}

Com referência aos dados coletados pelo monitoramento bimestral, verifica-se pela Tab. 2 que, para o primeiro e segundo bimestre, período correspondente a 10/08/05 e 10/10/05, não ocorreu modificação na estrutura do talude. Todavia, na borda das estacas, período correspondente a 10/12/05, só não ocorreu modificação nas estacas 1 e 2 . A estaca com maior erosividade foi a de número 4 , com $0,50 \mathrm{~m}$, posteriormente, as estacas $5,3 \mathrm{e}$ 6 , com 0,49 m, 0,35 m e 0,19 m, respectivamente, apresentaram elevado grau de erosividade. Os dados obtidos na última coleta são conseqüência da intensidade pluviométrica nos meses de novembro e dezembro. Observa-se no quarto e quinto bimestres, correspondentes a 10/02/06 e 10/04/06, respec-tivamente, modificações nas bordas das estacas devido às precipitações dos meses de janeiro e meados de março. Fato identificado na Tab. 2

No que se refere à aferição do dia 10/06/06, nota-se claramente a evolução do processo erosivo, quando apenas duas estacas não apresentaram erosividade perceptível (estacas 3 e 4). A estaca que indica maior dinâmica é a de número 2 , com apenas $0,92 \mathrm{~m}$ de distância entre a vertente e a estaca. Fato preocupante, uma vez que a estaca encontra-se fixada junto ao alicerce de uma residência acompanhada de um pequeno muro de contenção, como se observa na Tab. 1 e Fig. 3. Outra questão que merece atenção é o fato de que as obras de contenção implementadas pelo poder público nas mais variadas esferas (federal, estadual e municipal) não são monitoradas. É comum identificar, in loco, canos, lonas plásticas, muros de arrimo, escadarias, canaletas de drenagem, todos sem nenhum programa de manutenção por parte dos órgãos públicos. 
Tabela 2 Monitoramento da voçoroca.

\begin{tabular}{c|c|c|c|c|c|c}
\hline \multirow{2}{*}{$\begin{array}{c}\text { Número de } \\
\text { Estacas }\end{array}$} & \multicolumn{7}{|c}{ Distância entre borda e estaca $(\mathbf{m})$} & $\mathbf{1 0 / 0 2 / 0 6}$ & $\mathbf{1 0 / 0 4 / 0 6}$ & $\mathbf{1 0 / 0 6 / 0 6}$ \\
\cline { 2 - 8 } & $\mathbf{1 0 / 0 8 / 0 5}$ & $\mathbf{1 0 / 1 0 / 0 5}$ & $\mathbf{1 0 / 1 2 / 0 5}$ & 2,29 & 1,82 & 1,77 \\
\hline $\mathbf{1}$ & 2,46 & 2,46 & 2,46 & 0,98 & 0,93 & 0,92 \\
\hline $\mathbf{2}$ & 1,12 & 1,12 & 1,12 & 1,53 & 1,44 & 1,44 \\
\hline $\mathbf{3}$ & 1,90 & 1,90 & 1,55 & 1,15 & 1,11 & 1,11 \\
\hline $\mathbf{4}$ & 1,67 & 1,67 & 1,17 & 1,45 & 1,44 & 1,25 \\
\hline $\mathbf{5}$ & 1,55 & 1,55 & 1,46 & 1,44 & 1,40 & 1,31 \\
\hline $\mathbf{6}$ & 1,63 & 1,63 & 1,44 & & & \\
\hline
\end{tabular}

Como resultado da pesquisa, objetivou-se um diagnóstico geoambiental da região alvo dos estudos. Para tanto, foi utilizado o método de identificação e avaliação dos impactos com base nas idéias de LEOPOLD (1994) e GOMEZ (1994) adaptadas por NIÉDJA OLIVEIRA (1998). Empregou-se então uma avaliação de múltiplos critérios, adaptada do modelo Matricial, para identificar e avaliar as transformações ocorridas a partir de uma série de ações de gênese antrópica atuando sobre os fatores e elementos naturais, os quais propiciaram a identificação e enumeração de impactos (Tab. 3). As ações, os fatores e os elementos estiveram em consonância de $95 \%$ com os impactos identificados. Com a identificação dos impactos atuantes foi possivel a avaliação qualitativa e quantitativa, levando-se em consideração critérios como caráter do impacto, certeza, tipo, tempo em aparecer, magnitude, importância, duração e reversibilidade.

Tabela 3 Impactos identificados através das ações, fatores e elementos.

\begin{tabular}{|c|c|c|}
\hline ACCÕES & FATORES E ELEMENTOS & IMPACTOS \\
\hline $\begin{array}{l}\text { A. } \text { Corte ou Retirada da vegetação } \\
\text { B. Atividade Pecuária Bovina } \\
\text { C. Atividade Industrial } \\
\text { D. Obras de Engenharia } \\
\text { E. Instalação de Saneamento } \\
\text { básico incipiente } \\
\text { F. Construção civil } \\
\text { G. Cortes das barreiras } \\
\text { H. Cultivo de árvores frutiferas } \\
\text { I. Implantação de Estradas }\end{array}$ & $\begin{array}{ll}\text { I. } & \text { Solo } \\
\text { II. } & \text { Relevo } \\
\text { III. } & \text { Hidrologia } \\
\text { IV. } & \text { Alteração da estética da paisagem } \\
\text { V. } & \text { Indústria de construção } \\
\text { VI. } & \text { Comércio } \\
\text { VII. } & \text { Economia } \\
\text { VIII. } & \text { Flora e fauna terrestre } \\
\text { IX. } & \text { Uso do solo } \\
\text { X. } & \text { População } \\
\text { XI. } & \text { Vetores de germes } \\
& \text { patogênicos }\end{array}$ & 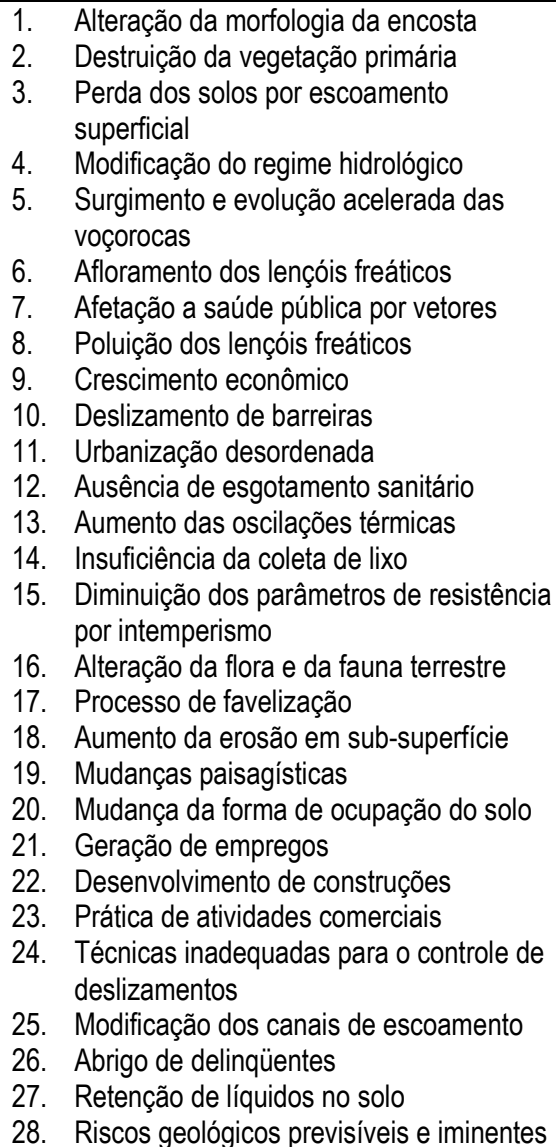 \\
\hline
\end{tabular}


Como resultados de investigação de aerofotocartas, disponibilizadas pelo CONDEPE/FIDEM, verifica-se a seguir que:

- Aereofotocarta № 81/15; escala 1:2.000; ano: 1974; data da plotagem: 02/05/75; poucas habitações, resumindo-se nas áreas de topo; vertente: cotação máxima: $50 \mathrm{~m}$, cotação mínima: $20 \mathrm{~m}$.

A expansão urbana fazia-se no topo da vertente $(50 \mathrm{~m}), 0$ restante era coberto por vegetação e na mais baixa cotação (20 m) desenvolvia-se cultura de subsistência, em face de ser uma área dispersora de água, com ribeiras, permanecendo com um bom volume hídrico como conseqüência da vegetação nativa. Neste ano, Camaragibe ainda não era município, fazia parte do município de São Lourenço da Mata, como distrito, sendo esse o período de início do processo mais intensificado de urbanização de seu território.

- Areofotocarta № 81/05; escala 1:10.000; ano: 1975; data da plotagem: 05/05/75. Com aparência de aumento de área desnudada, por um provável processo da construção civil. Movimento que não se encontra concentrado em um só local, mas se apresenta disperso; vertente: cotação máxima: 100 m, cotação mínima: $40 \mathrm{~m}$.

A paisagem, semelhante a do ano anterior da aerofotocarta No 81/15, começa a receber maiores alterações com a intensificação da retirada da cobertura vegetacional, contribuindo para o aumento da taxa de infiltração e absorção de água pelo solo, aumentando o risco das mesmas atingirem a área de cisalhamento e o provável deslizamento.

- Aereofotocarta № 81/05; escala: 1:10.000; ano: 1984; data da plotagem,: 17/06/84, observa-se aumento significativo do processo de urbanização da área; vertente: cotação máxima: 100 m, cotação mínima: $40 \mathrm{~m}$.

Pôde-se identificar o aumento da urbanização da área, norteando-se através de quase toda a ocupação da área de cimeira e 0 início da ocupação de vertente até sua base, com áreas de equidistância das curvas de nível entre 100 e $80 \mathrm{~m}$. Percebe-se a devastação da cobertura natural pelo desmatamento e corte incorreto da vertente como trincheiras, aterros e acúmulo de resíduos domésticos intensificando as probabilidades de riscos geológicos. Foi notória, também, a diminuição do volume de água dos cursos fluviais alimentados pela zona dispersora de água, contribuindo para que as vertentes da área de estudo se tornassem ainda mais desnudadas.

Em relação à imagem de fotografia aérea; escala: 1:6.000; data da tomada: 02/05/74, materializa-se uma urbanização da vertente antes inexistente, no entanto, com a cobertura vegetal degradada, quatro manchas com a vegetação ainda preservada, manchas menos densas (claras) representadas por capoeiras.

No que se refere à imagem de fotografia aérea; escala: 1:6.000; ano 1987, identifica-se alto grau de urbanização, tendo do lado direito da entrada de acesso à vertente duas casas, uma no segundo degrau e outra no terceiro degrau da vertente; do lado esquerdo, nota-se uma vegetação pouco densa.

De acordo com a metodologia proposta por LEOPOLD (1994) e GOMEZ (1994), após a identificação das ações atuantes, na área objeto de estudo, dos fatores e elementos envolvidos e da enumeração dos impactos, foi possivel avaliar qualitativa e quantitativamente cada impacto (Tab. 4). Na avaliação qualitativa considerou-se os seguintes parâmetros: a primeira coluna referese à natureza do impacto (negativo ou positivo); a segunda, à probabilidade do impacto acontecer ( $\mathrm{c}$ - certo, $\mathrm{p}$ - provável, i improvável); a terceira, à conseqüência do impacto ( $\mathrm{Pr}$ consequêencia direta, Sc- conseqüência indireta e Ac conseqüências individuais, mas que podem dar origem a outros maiores); a quarta e última coluna da Avaliação Qualitativa aborda o tempo necessário para acontecer (c - dentro de 6 meses, $\mathrm{m}$ - de 6 meses a 3 anos, $I-3$ anos ou mais).

Ainda no tocante à Tab. 4, a Avaliação Quantitativa dividese em quatro colunas, em que a primeira indica a área de abrangência do impacto ( 1 - área afetada inferior a 1 ha, 2- área afetada entre 1 e 10 ha, 3 - área afetada maior que $10 \mathrm{ha}$ ); a segunda coluna indica a importância relativa que 0 impacto tem com os demais impactos (0 - sem importância, 1 - menor, 2 moderada, 3 - maior); a terceira coluna refere-se ao tempo suposto para a duração do impacto ( 1 - menos de 1 ano, 2 - entre 1 e 5 anos, 3 - mais de 5 anos); a quarta coluna avalia a reversibilidade da área, após o término do impacto (1 - reversível, 2 - irreversível). 0 valor de cada impacto é calculado com a multiplicação do primeiro pelo segundo termo e a adição do terceiro e quarto. 0 maior valor de impacto estimado foi 13 , representado pela destruição da vegetação primária, modificação do regime hidrológico, poluição dos lençóis freáticos e riscos geológicos previsíveis e iminentes. Todos de natureza negativa.

Pontua-se na Tab. 5 a identificação dos impactos e sua ocorrência em cada ação antrópica realizada no campo. A presente tabela permite entender as múltiplas conseqüências que cada ação imprime no local. Os fatores e elementos que envolvem a maior quantidade de impactos foram os sócioeconômicos, com 91 impactos e os fatores físicos, envolvendo 89 impactos. 
Tabela 4 Valoração qualitativa e quantitativa dos impactos.

\begin{tabular}{|c|c|c|c|c|c|c|c|c|c|c|}
\hline & Impactos & \multicolumn{4}{|c|}{ Avaliação Qualitativa } & \multicolumn{4}{|c|}{ Avaliação Quantitativa } & Valor do Impacto \\
\hline 1 & Alteração da morfologia da encosta & - & C & $\mathrm{Pr}$ & $\mathrm{m}$ & 2 & 3 & 3 & 1 & 10 \\
\hline 2 & Destruição da vegetação primária & - & c & $\operatorname{Pr}$ & c & 3 & 3 & 3 & 1 & 13 \\
\hline 3 & Perda dos solos por escoamento superficial & - & $\mathrm{c}$ & $\operatorname{Pr}$ & c & 1 & 3 & 3 & 0 & 6 \\
\hline 4 & Modificação do regime hidrológico & - & $\mathrm{p}$ & Sc & $\mathrm{m}$ & 3 & 3 & 3 & 1 & 13 \\
\hline 5 & Surgimento e evolução acelerada das voçorocas & - & $\mathrm{c}$ & $\operatorname{Pr}$ & c & 1 & 3 & 3 & 0 & 6 \\
\hline 6 & Afloramento dos lençóis freáticos & - & $\mathrm{p}$ & Sc & $\mathrm{m}$ & 1 & 3 & 2 & 1 & 6 \\
\hline 7 & Riscos à saúde pública por vetores patógenos & - & c & Ac & c & 3 & 3 & 2 & 0 & 11 \\
\hline 8 & Poluição dos lençóis freáticos & - & $\mathrm{p}$ & Sc & I & 3 & 3 & 3 & 1 & 13 \\
\hline 9 & Crescimento econômico & + & $\mathrm{p}$ & $\operatorname{Pr}$ & $\mathrm{m}$ & 3 & 2 & 2 & 0 & 8 \\
\hline 10 & Aumento dos movimentos de massa & - & c & $\operatorname{Pr}$ & c & 3 & 3 & 3 & 0 & 12 \\
\hline 11 & Urbanização desordenada & - & c & $\mathrm{Pr}$ & I & 3 & 3 & 3 & 0 & 12 \\
\hline 12 & Ausência de esgotamento sanitário & - & c & Ac & $\mathrm{m}$ & 3 & 3 & 3 & 0 & 12 \\
\hline 13 & Aumento das oscilações térmicas & - & c & Sc & $\mathrm{m}$ & 3 & 2 & 3 & 1 & 10 \\
\hline 14 & Insuficiência da coleta de lixo & - & c & Sc & C & 3 & 2 & 2 & 0 & 8 \\
\hline 15 & Alteração da flora e da fauna terrestre & - & c & $\mathrm{Pr}$ & c & 3 & 3 & 3 & 0 & 12 \\
\hline 16 & Processo de favelização & - & c & $\operatorname{Pr}$ & C & 3 & 2 & 3 & 0 & 9 \\
\hline 17 & Aumento da erosão em sub-superfície & - & c & Ac & $\mathrm{m}$ & 2 & 2 & 3 & 0 & 7 \\
\hline 18 & Mudanças paisagísticas & - & c & Ac & $\mathrm{m}$ & 3 & 2 & 3 & 1 & 10 \\
\hline 19 & Mudança da forma de ocupação do solo & - & c & $\operatorname{Pr}$ & $\mathrm{m}$ & 3 & 2 & 3 & 0 & 9 \\
\hline 20 & Geração de empregos & + & $\mathrm{p}$ & $\operatorname{Pr}$ & $\mathrm{m}$ & 3 & 2 & 3 & 0 & 9 \\
\hline 21 & Desenvolvimento de construções & + & p & Sc & $\mathrm{m}$ & 3 & 1 & 2 & 0 & 5 \\
\hline 22 & Prática de atividades comerciais & + & $\mathrm{c}$ & $\mathrm{Pr}$ & c & 2 & 2 & 3 & 0 & 7 \\
\hline 23 & Técnicas inadequadas para o controle de deslizamentos & - & c & Ac & $\mathrm{m}$ & 3 & 3 & 3 & 0 & 12 \\
\hline 24 & Modificacão dos canais de escoamento & - & c & $\mathrm{Pr}$ & c & 3 & 2 & 2 & 0 & 8 \\
\hline 25 & Abrigo de delinqüentes & ـ & $\mathrm{p}$ & Ac & c & 3 & 2 & 3 & 0 & 9 \\
\hline 26 & Retencão de líquidos no solo & - & $\mathrm{c}$ & Sc & c & 2 & 3 & 2 & 0 & 8 \\
\hline 27 & Riscos geológicos previsíveis e iminentes & - & c & $\mathrm{Pr}$ & $\mathrm{m}$ & 3 & 3 & 3 & 1 & 13 \\
\hline
\end{tabular}

Uma importante etapa da pesquisa foi a confirmação de estudos laboratoriais com as hipóteses da pesquisa, realizados pelo LAGESE/UFPE. Tais análises permitiram afirmar a maior representatividade da parcela argila em todas as amostras (Fig. 10), um importante dado que atua como agente catalisador dos processos de movimentos de massa na área. A grande representatividade da argila contribui, de forma direta, para que todo material sobrejacente, ora friável devido à baixa capacidade de infiltração e taxa de aeração, seja remobilizado para as áreas mais baixas, em função da própria ação da gravidade. Essa situação torna-se mais grave, se for considerada a presença de bananeiras (Fig. 4), vindo a concentrar o maior acúmulo de água nas vertentes monitoradas.

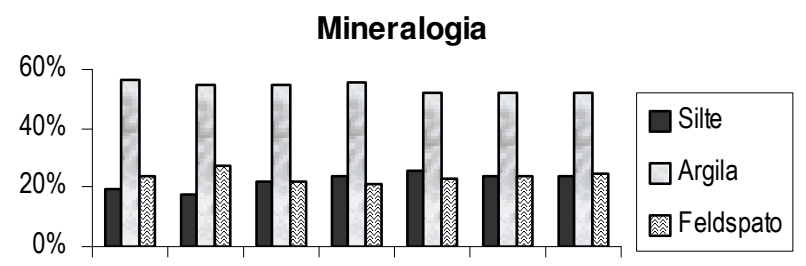

A 1 A2 A3 A4 B1 B2 B3

\section{Amostras}

Figura 10 Mineralogia das amostras coletadas na área de estudo.
Somando-se a água acumulada através da cultura doméstica, com os esgotos a céu aberto, a tubulação de abastecimento de água com rupturas e 0 índice pluviométrico: atingindo no mês de junho/2006, 403,4 mm e para o mês de agosto/2005 com $306 \mathrm{~mm}$, meses que acumularam os maiores riscos geológicos da área em questão. Fato que se confirma através do grau de erosividade das estacas afixadas, quando se observa na Fig. 12, a significativa redução do espaço entre estaca e borda, resultante de todos os fatores descritos.

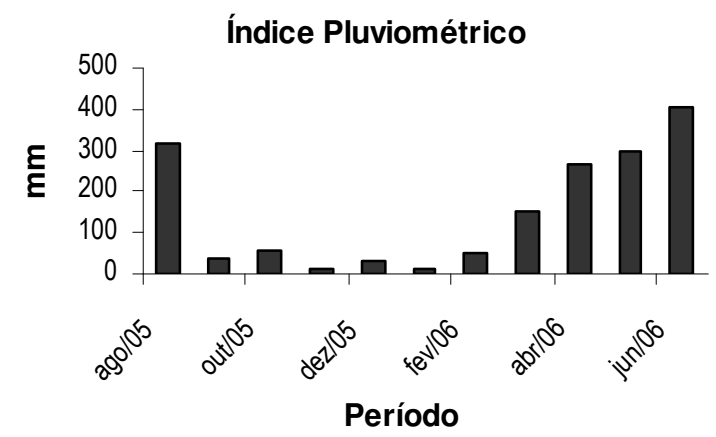

Figura 11 Índice pluviométrico da Estação Camaragibe. Fonte: LAMEPE/ITEP (2005/2006). 
Tabela 5 Matriz de identificação de impactos no bairro de Tabatinga-Camaragibe/PE.

\begin{tabular}{|c|c|c|c|c|c|c|c|c|c|c|}
\hline \multicolumn{2}{|c|}{$\begin{array}{l}\text { Fatores e elementos } \\
\text { ambientais }\end{array}$} & A & B & C & D & $\begin{array}{c}\text { Ações } \\
E\end{array}$ & $\mathbf{F}$ & G & $\mathrm{H}$ & 1 \\
\hline \multirow[t]{3}{*}{ Físico } & Solo & $\begin{array}{l}1,2,3 \\
15,18\end{array}$ & $\begin{array}{c}2,7,15,18 \\
19\end{array}$ & $\begin{array}{l}2,3,18 \\
19,20 \\
21,22\end{array}$ & $\begin{array}{c}18,192 \\
0\end{array}$ & $3,24,26$ & $\begin{array}{c}10,11 \\
16,19 \\
21,24,26\end{array}$ & $\begin{array}{c}1,3,5,6,11 \\
, 18,19\end{array}$ & $\begin{array}{c}1,2 \\
15,1826\end{array}$ & $\begin{array}{c}1,2,35 \\
19\end{array}$ \\
\hline & Relevo & $\begin{array}{c}1,2,3,17,1 \\
827\end{array}$ & $20,22,24$ & 18 & $2,5,10$ & $12,18,24$ & $\begin{array}{l}10,11 \\
16,17 \\
23,27\end{array}$ & $\begin{array}{c}1,5,6,17,2 \\
7\end{array}$ & 10,1518 & $5,6,23$ \\
\hline & Hidrologia & 4 & - & - & - & $4,8,12$ & - & 24 & 4,26 & 24 \\
\hline \multirow[t]{2}{*}{ Biótico } & $\begin{array}{l}\text { Flora e } \\
\text { Fauna } \\
\text { terrestre }\end{array}$ & 2,18 & 2,18 & 2,18 & $2,15,18$ & 2,15 & 2,15 & 15,18 & 15 & 15 \\
\hline & $\begin{array}{l}\text { Vetores de } \\
\text { germes } \\
\text { patogênicos }\end{array}$ & 7 & 7 & - & - & 7 & - & - & - & - \\
\hline Perceptual & $\begin{array}{l}\text { Alteração da } \\
\text { estética da } \\
\text { paisagem }\end{array}$ & $1,18,27$ & 2,18 & 18 & 18 & 18 & 18 & 18 & 18 & 18 \\
\hline \multirow[t]{5}{*}{$\begin{array}{l}\text { Sócio- } \\
\text { econômico }\end{array}$} & $\begin{array}{l}\text { Indústria de } \\
\text { construção }\end{array}$ & $\begin{array}{c}2,10,13,1 \\
5,18 \\
23,24\end{array}$ & - & $19,20,22$ & $\begin{array}{c}19,20,2 \\
2\end{array}$ & 8,24 & 20,21 & 11,23 & - & 15,24 \\
\hline & Comércio & 22 & 20,22 & 20 & 20 & - & $20,21,22$ & - & 9,22 & 9,22 \\
\hline & Economia & 20,22 & $9,20,22$ & $9,20,22$ & $\begin{array}{c}9,20,21 \\
, 22\end{array}$ & - & $\begin{array}{c}9,20,21,2 \\
2\end{array}$ & - & 9,22 & 9,22 \\
\hline & Uso do solo & $\begin{array}{c}1,11,16,1 \\
9,18\end{array}$ & 9,22 & 19,22 & 18,19 & 24,19 & $11,16,19$ & 18,1927 & 18,19 & 18,23 \\
\hline & População & 11,16 & 20,22 & 20,22 & 20,22 & - & 20,21 & 23 & 22 & $9,20,22$ \\
\hline
\end{tabular}

$\mathrm{Na}$ Fig. 12 verificou-se que para os meses de agosto, outubro e dezembro de 2005, o processo erosivo foi nulo. 0 processo de erosão iniciou-se no mês de fevereiro de 2006, intensificando-se de abril a junho de 2006. Nos meses de agosto, outubro e dezembro de 2005 não foi observada erosão na estaca 2. Entretanto, do mês de fevereiro de 2006 a junho, ocorreu um processo acelerado de erosão. Nos meses de agosto a outubro de 2005 não houve erosão na estaca 3, que foi aumentada, contudo, nos meses de dezembro de 2005, fevereiro, abril e junho de 2006. A estaca 4 mostrou-se em equilíbrio dentro do processo de erosividade nos meses de agosto a outubro de 2005 , entretanto, com maior índice de erosividade nos meses de de- zembro de 2005 a fevereiro de 2006, culminando com a intensificação de erosão entre abril e junho de 2006. A estaca 5 manteve-se em equilíbrio para os meses de agosto, outubro e dezembro de 2005 , continuando neste processo em fevereiro de 2006, passando a desequilibrar em abril e atingindo o ápice erosivo em junho de 2006. Por fim, a estaca 6 manteve-se equilibrada em agosto e outubro, intensificando o processo erosivo nos meses de dezembro de 2005, fevereiro e abril de 2006, atingindo a maior ação erosiva no mês de junho de 2006. Pode-se avaliar dentro do sistema de correlação de erosão com os índices pluviométricos, considerando-se também as ações exógenas produzidas pelo homem. 


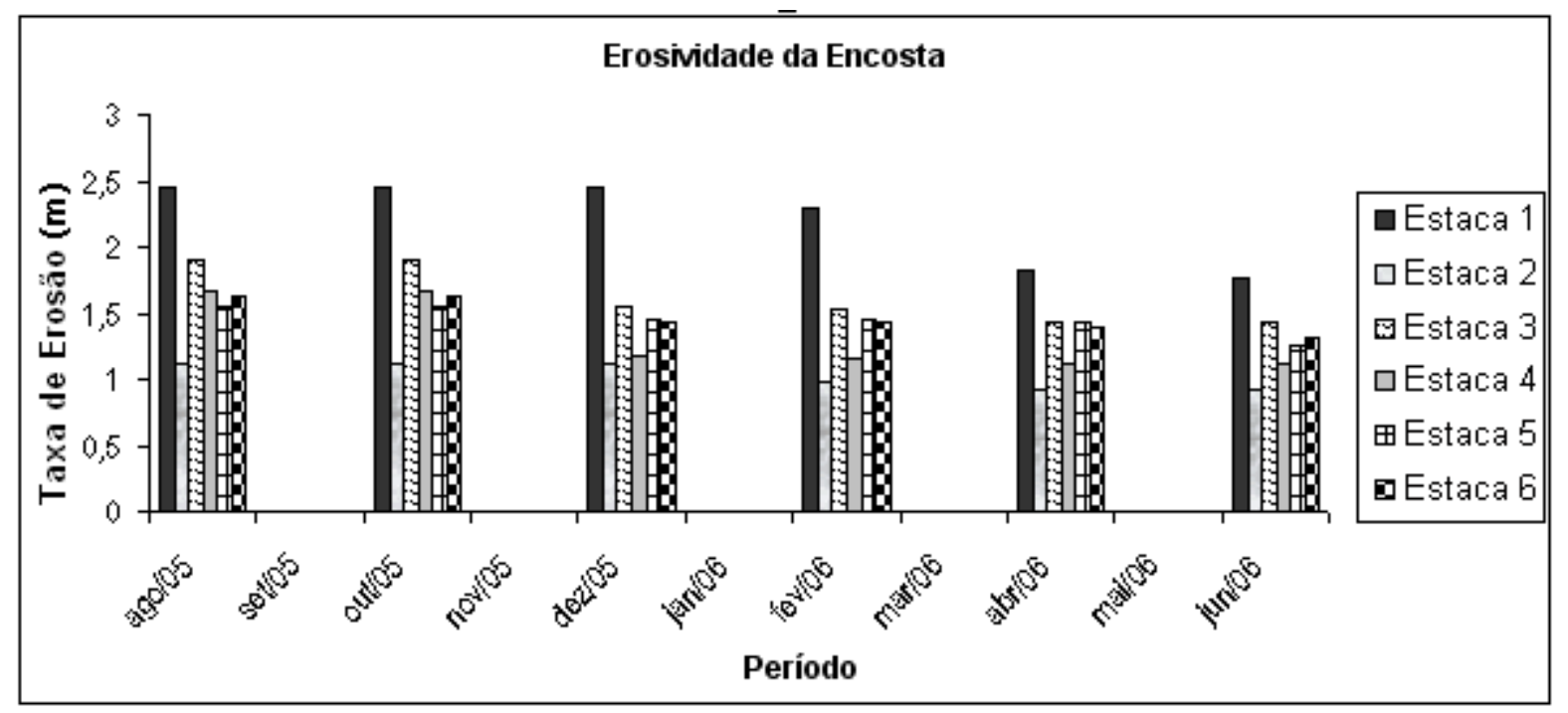

Figura 12 Dinâmica das vertentes, taxa de erosão (m).

\section{Conclusões}

A pesquisa trouxe à tona os fatores históricos que justificam a forma de ocupação do espaço, seu modelo socioeconômico, demográfico e suas condições de gestão ambiental, que caracterizam o município e dão subsídios para a continuidade de estudos da problemática em questão. Pode-se tomar, por destaque, a falta de políticas públicas efetivas que venham monitorar, com eficácia, as áreas de risco geológico no sentido de possibilitar condições saudáveis e o direito de sua sobrevivência.

0 movimento de massa vem sendo um reflexo da desordem urbana na área, cuja população é de baixa renda e se fixa em área de risco geológico das colinas do Grupo Barreiras. Essa população é responsável por cortes para fixação das residências, desmatamento e produção de lixo que permeia e impede 0 escoamento dos canais. Falta 0 direcionamento das políticas públicas para manutenção e equilíbrio dos taludes.

0 escorregamento complexo da área em pauta leva a sugerir uma determinada cota de escavação, o talude projetado pode ser incompatível com 0 ângulo de atrito e atitude das descontinuidades presentes nos horizontes de saprólito ou rocha alterada. A presença do nível d'água, que ocorre freqüentemente no horizonte de saprólito junto ao topo da rocha pouco alterada, a rocha sã muito fraturada, pode vir a ser o desencadeador do processo do escorregamento. Esta primeira ruptura geralmente se processa em pequeno volume e é, via de regra, do topo planar ou em cunha. $O$ desencadeamento de rupturas planares ou em cunha no sopé do talude foi condicionado por estruturas remanescentes da rocha matriz. Além desses fatores, a redução de resistência ao cisalhamento, que favoreceu a percolação da água no talude, foram observadas ao longo de toda massa fendas de tração e trincas. A ocorrência de pequena quantidade de chuva por uma questão sazonal leva a crer que na estação chuvosa subseqüente 0 processo pode se acelerar e dar origem a uma ruptura transversal ou rotacional de grande parte do talude. Este escorregamento translacional vem originando outros, como os escorregamentos rotacionais em solo.

Com a aplicação da metodologia matricial, foi possível definir detalhadamente os impactos atuantes na área, cujas ações passaram a intervir nos fatores e elementos, possibilitando diagnosticar a diversidade de impactos, com 9 ações, 11 fatores e elementos e 27 impactos. Ocorrendo um sistema de interação da ordem de $95 \%$. Para as análises da avaliação qualitativa e quantitativa foram verificados 23 impactos negativos e apenas 4 positivos, cujos valores negativos chegaram a atingir 0 valor máximo de 13 pontos, particularizado na Tab. 4.

No que compreende os fatores e elementos ambientais, identificaram-se: o fator físico, biótico, perceptual e socioeconômico, todos passando a ser fatores geradores de impactos na área de pesquisa, favorecendo 0 processo de degradação ambiental. 
OLIVEIRA, M.G.A.; CARVALHO, J.A.R.; SANTANA, P. H. (2006). Geomorphologic characterization and environmental evaluation of the fragility of the sources in Tabatinga, city of Camaragibe, PE. Revista do Departamento de Geografia, n. 19, p. 92-103.

\begin{abstract}
The objective of this research is to analyze, in plan of evolution, the environmental Geomorphology of the forms that, as dynamic object, reflects inductive environment to the occurrence of landslides, evaluating the factors directly and indirectly responsible for the soil resistance to erosion. This is a proposal of integrated action that offers opportunities to the environmental Geomorphologic characterization of the mass movement system in the hill areas of accumulation Glacis in Tabatinga neighborhood, in the municipality of Camaragibe, inserted in the Barreiras Group. The methodology was comprised of mineralogical analyses, bimonthly monitoring of hills and the materializing erosion of its edges. Identification and evaluation of the impacts were based on LEOPOLD (1994) and GOMEZ (1994), adapted by OLIVEIRA (1998). As a result of the mineralogical analysis, clay predominance was diagnosed $(56.8 \%)$. The sources suffer significant loss according to the monitored areas. As for the impact evaluation, 27 were identified. From the total, only 4 were positives.
\end{abstract}

Key words: Environmental Degradation; Mass Movement; Landslide; Geological risk.

Recebido em 16 de novembro de 2005, aceito em 3 de setembro de 2006.

\section{Referências}

GÓMEZ, O. (1994) Evaluación de Impacto Ambiental. Ed.

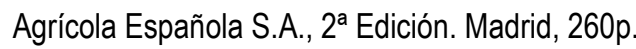

GUIDICINI, G.; NIEBLE, C. M. (1984) Estabilidade de Taludes Naturais e de Escavação. Edgand. B1. cher. $2^{\text {TM }}$ p. 194.

KÖPPEN, J. W. (1948) Climatólogia con uno Estudio de los Climas de la Tierra. Fondo de Cultura Econômica - Mexico,. p. 478.
LEOPOLD, A. (1994) Matriz de evaluación de impactos. En: Curso Master E. I. A. Instituto de Investigaciones Ecológicas. Málaga, Módulo 7: 57-58

OLIVEIRA, N. (1998) Problemas Geomorfológico - Ambientales de las Restingas y Mangles Em Pernambuco y Cuba. Tese de Doutoramento Ministério de Ciências y Tecnologia y Médio Ambiente. I.G.T. Academia de Ciências de Cuba. La Habana. 